\section{Homeopathy is where the harm is: five unethical effects of funding unscientific 'remedies'

\author{
$\underset{\text { tororos }}{\text { David M Shaw }}$ \\ CHOICE
}

Homeopathic medicine is based on the two principles that 'like cures like' and that the potency of substances increases in proportion to their dilution. ${ }^{1}$ In November 2009 the UK Parliament's Science and Technology Committee heard evidence on homeopathy, with several witnesses arguing that homeopathic practice is 'unethical, unreliable and pointless'. Although this increasing scepticism about the merits of homeopathy is to be welcomed, the unethical effects of funding homeopathy on the NHS are even furtherreaching than has been acknowledged.

There are NHS homeopathic hospitals in Bristol, Liverpool, Glasgow and London, and the Medicines and Healthcare Products Regulatory Agency (MHRA) has judged homeopathic treatments worthy of licensing. ${ }^{3} 4$ Many patients seem to believe that homeopathic treatment helps them, as sales of homeopathic remedies in the UK increased by $24 \%$ in the 5 years to 2007. The British Homeopathic Association encourages visitors to its website to contact their MPs and primary care trusts and the media in order to communicate that their homeopathic treatment "was effective, especially in comparison with conventional medicine'. ${ }^{6}$ At the committee hearing, many experts argued that there was no evidence that homeopathy is effective; unsurprisingly, expert homeopaths argued the contrary. This may be due to two different conceptions of efficacy, with the homeopaths arguing that their practice is effective inasmuch as it is as good as placebo, and the other experts adopting the higher standard (but still the lowest for evidence-based medicine) of 'more effective than placebo'. But if patients believe that they are benefiting, and homeopathic remedies provide a

Dental School, Faculty of Medicine, University of Glasgow, Glasgow, UK

Correspondence to Dr David Martin Shaw, University of Glasgow, 378 Sauchiehall Street Glasgow G2 9JZ, UK; d.shaw@dental.gla.ac.uk helpful placebo effect, then what's the problem?

The first and most important potential unethical effect of homeopathy is that patients seek homeopathic remedies instead of, rather than as well as, traditional medicine. Even for minor ailments, this could result in greater suffering for the patient than would be the case had they remained within mainstream medicine. But in the case of serious illness, seeking homeopathic treatment could be deadly, and the WHO recently warned against homeopathic remedies for tuberculosis, malaria and HIV. ${ }^{7}$ Homeopathic practitioners in the UK may not be recommending such remedies, but some have recommended to patients that they should not have their children vaccinated, resulting in a greater chance of harm to children, both directly to those not vaccinate and through potential loss of herd immunity. ${ }^{5}$ Homeopathic remedies are not actively harmful, as they contain no active molecules: nonetheless, the harm done by omitting evidence-based medical treatment is potentially significant.

Second, it is ethically dubious to spend NHS funds on treatment that has no evidence base (beyond that of placebo effect); NHS patients rightly expect valuable resources to be well spent. This is all the more true if homeopathic remedies do not actually help the patient and they then have to seek conventional treatment, in effect making the NHS pay twice. Furthermore, any money spent on homeopathy in the NHS could have been spent elsewhere within the organisation on more efficacious treatments. If homeopathic remedies are unproven and might lead to extra conventional expense, and the money could have been better spent elsewhere, we actually have three reasons not to fund homeopathy on the NHS. In response, it could be argued that homeopathic treatments are very cheap; this is certainly true, but the NHS has only finite resources, and every penny counts.

The third ethical issue with homeopathy is that it can involve deceiving the patient; indeed, if the only effect is placebo, it is probable that deception is essential to the practice of homeopathy. If a patient is told that he is being given a placebo, the placebo effect will probably be lost $^{8}$; homeopaths tend to avoid this issue by explaining the 'scientific basis' of the treatment and saying that it has 'worked' for other people. This is perhaps being economical with the truth rather than outright deception, but the primacy of the principle of respect for autonomy and informed consent in modern medicine demand more complete disclosure of information. In order to meet these standards, homeopaths would have to be entirely transparent about the evidence base for any treatment-and doing so might well negate any effectiveness. It is possible that patients would still benefit from the time and discussion with the homeopathic practitioner (indeed this time and attention might form an important part of the placebo effect), but the central deception of the efficacy of homeopathic dilution is essentially unethical.

A less direct ethical issue is that the NHS's support for homeopathy could weaken patient confidence in the organisation, and in science and medicine more generally. If our national health body is prepared to fund treatment that is no better than the minimum standard for efficacy in evidence-based medicine, then the NHS is guilty of double standards of evidence-one for evidence-based medicine, and another for homeopathy. It is true that almost half of the treatments provided by the NHS are of unknown efficacy, ${ }^{9}$ but at least doctors have reason to believe that many of these treatments work - the purported mechanism behind homeopathy has no scientific basis, and it is misleading to compare unproven homeopathic remedies without a rational basis with unproven medical remedies with clinical reasoning behind them. ${ }^{10}$ Furthermore, the MHRA's licensing of homeopathic products weakens that organisation's claim to be evidence-based, and also plays a role in 'undermining the rational basis for medicine'. ${ }^{11}$ In effect, if the public believes that homeopathy is medical science, then this devalues both science and medicine. (The MHRA guidance for approving a licence for homeopathic remedies states that applicants must 'sufficiently demonstrate that UK homoeopathic practitioners would accept the efficacy of the product for the indications sought', which cravenly leaves it up to homeopaths to decide whether a product should get a 
licence. ${ }^{4}$ Furthermore, the licence itself might be illegal. ${ }^{12}$ )

The fifth and final unethical effect is that funding homeopathy distracts attention from the fact that there are other complementary therapies that are efficacious. Members of the public who are unconvinced by the merits of homeopathy are likely to think the same thing about all complementary/alternative medicine, some of which is proven to be better than placebo. It is particularly unfortunate that hospitals offering some effective complementary therapies are called 'homeopathic hospitals' ${ }^{13}$ Homeopathy is not simply inferior to mainstream medicine, it is inferior to some forms of complementary medicine as well.

To conclude, it is likely that homeopathy is where the harm is. Although homeopathic remedies do not directly harm patients, it is very possible that harm could befall homeopathy patients who refrain from seeking traditional medicine. Patients in the NHS could be indirectly harmed if funds are spent on homeopathy that could have been spent on mainstream care. Patients who are prescribed homeopathic treatments are very possibly being deceived, and thus are being treated unethically. And home- opathy is currently weakening public confidence in the NHS, the MHRA and science and medicine in general, and also doing a disservice to efficacious forms of complementary medicine. Most of these unethical effects could be minimised by withdrawing NHS funding for homeopathic practice, and educating the public about the lack of an evidence base for homeopathy. In other words, it would be more ethical for the NHS to stick to treatments of proven worth. There was once a homeopathic hospital in Tunbridge Wells, but it was closed because "the NHS has to decide the best use of money on the evidence of clinical effectiveness'. ${ }^{14}$ Other NHS trusts would do well to follow this example.

Funding Internally funded by the University of Glasgow.

Competing interests None.

Provenance and peer review Not commissioned; externally peer reviewed.

Received 9 December 2009

Accepted 16 December 2009

J Med Ethics 2010;36:130-131.

doi:10.1136/jme.2009.034959

\section{REFERENCES}

1. British Homeopathic Association. About homeopathy. http://www.britishhomeopathic.org/ about homeopathy/ (accessed 12 Aug 2009).
2. O'Dowd A. Giving homeopathy on the NHS is unethical and unreliable, MPs are told. BMJ 2009;339:b5080.

3. British Homeopathic Association. NHS homeopathic treatment. http://www. britishhomeopathic.org/getting treatment/ homeopathy_in_the nhs/ (accessed 12 Aug 2009).

4. Cohen $\mathbf{D}$. Drugs agency grants its first licence to homoeopathic product. BMJ 2009;338:b2055.

5. Ernst E. Harmless homeopathy? Int J Clin Rheumtol 2009;4:7-10.

6. British Homeopathic Association. What you can do to help. http://www.britishhomeopathic.org/ what you can do/campaign for homeopathy/ what_you_can_do_to_help.html (accessed 12 Aug 2009).

7. Mastha $\mathbf{0}$. WHO warns against using homoeopathy to treat serious diseases. BMJ 2009;339:b3447.

8. Shaw D. Prescribing placebos ethically. J Med Ethics 2009;35:97-9.

9. Clinical Evidence. How much do we know? http:// clinicalevidence.bmj.com/ceweb/about/knowledge. isp (accessed 12 Aug 2009).

10. Gordon $\mathbf{S}$. The evidence is sufficient (e-letter). BMJ http://www.bmi.com/cgi/eletters/339/nov27 2/ b5080\#226079 (accessed 12 Aug 2009).

11. Evans S. Back to square one. BMJ 2009;338: b2332.

12. Colquhoun D. MHRA label seems to be illegal. $B M J$ 2009;338:b2333.

13. University College London Hospitals. Our hospitals. http://www.uclh.nhs.uk/Our + hospitals/ Royal+London+Homoeopathic + Hospital.htm (accessed 12 Aug 2009).

14. $\quad$ BBC. NHS trust stops homeopathy funds. http:// news.bbc.co.uk/1/hi/england/kent/7015675.stm (accessed 12 Aug 2009). 